\title{
Adsorption of Sulfometuron and Other Anions on Pillared Clay
}

\author{
Tamara Polubesova,* Tomas Undabeytia, Shlomo Nir, Lubov Chertkova, \\ Henri Van Damme, and Faiza Annabi-Bergaya
}

\section{ABSTRACT}

The adsorption of several anions of agronomic and ecological importance, sulfometuron 2-[3-(4,6-dimethylpyrimidin-2-yl)ureidosulfonylbenzoic acid, sulfate, acetate, and chloride on pillared clay was studied. Pillared clay (PC) is a very effective adsorbent of anions from aqueous solutions. The fractions of sulfometuron adsorbed from aqueous solutions were more than $90 \%$ of added, but low solubility limited the added amounts. The maximal adsorbed amount of sulfate was $0.72 \mathrm{~mol}_{\mathrm{c}} \mathrm{kg}^{-1}$ and of acetate was $0.41 \mathrm{~mol}_{\mathrm{c}} \mathrm{kg}^{-1}$. Addition of 100 and $500 \mathrm{mM}$ of $\mathrm{NaCl}$ as the background electrolyte did not affect the adsorption of sulfometuron, but drastically reduced the adsorption of sulfate and acetate. Acetate at $\mathbf{1 0 0 0}$-fold larger excess competes with sulfometuron for the surface sites, but sulfate does not. Acetate decreased dramatically the adsorption of sulfate when both anions were added simultaneously, but acetate did not adsorb on the clay with pre-adsorbed sulfate. The sequence of adsorption affinity of anions to the $\mathrm{PC}$ surface is: sulfometuron $>>$ sulfate $>$ acetate $>>$ chloride. The binding coefficient was $12000 \mathrm{M}^{-1}$ for sulfometuron, $650 \mathrm{M}^{-1}$ for sulfate, $350 \mathrm{M}^{-1}$ for acetate, and $15 \mathrm{M}^{-1}$ for chloride. The dominant mode of sulfometuron adsorption on $\mathrm{PC}$ is via strong electrostatic interactions. The proposed interactions of sulfate with $\mathrm{PC}$ are outer- and inner-sphere complexation. The $\mathrm{pH}$ is reduced with sulfate adsorption and $\mathbf{A}$ is released. The proposed mode of acetate interactions with $\mathrm{PC}$ is mainly via inner-sphere complexation. In this case the $\mathrm{pH}$ increases with acetate adsorption, indicating exchange of acetate with surface hydroxyls, and Al is not released.

$\mathrm{P}$ ILLARED CLAYS are nanocomposite micro- and/or meso-porous materials prepared by intercalating bulky neutral or, most often, cationic species in the interlayer space of smectite clays (Lahav et al., 1978; Barrer, 1989; Bergaya, 1990; Bergaya et al., 1993b; Lagaly, 1995). The intercalated species act as props (pillars) that keep the clay layers apart and prevent them from collapsing under vacuum, at high temperatures, or under specific conditions (Bergaya, 1994). The pillaring process generates micro- and/or meso-porosity in the interlamellar spaces. Pillared clays have remarkable adsorption properties that are related both to the geometrical features of the porous spaces and to the specific interactions of the adsorbates with the pillars and the clay layers (Van Damme and Fripiat, 1985; Van Damme et al., 1986; Bergaya et al., 1993a; Bergaya, 1995). Environmental pollutants are adsorbed significantly on PCs (Zielke and Pinnavaia, 1988; Nolan et al., 1989). Modification of PCs with pre-adsorbed surfactants can improve their adsorptive properties (Srinivasan and Fogler, 1990;

T. Polubesova, T. Undabeytia, S. Nir, and L. Chertkova, Seagram Center for Soil and Water Sciences, Faculty of Agriculture, Food and Environmental Quality Sciences, The Hebrew Univ. of Jerusalem, Rehovot 76100, Israel. H. Van Damme and F. Annabi-Bergaya, Centre de Recherche sur la Matière Divisée CNRS and Université d'Orléans, 45071 Orléans cedex 2, France. Received 28 June 1999. *Corresponding author (polubeso@agri.huji.ac.il).

Published in J. Environ. Qual. 29:948-954 (2000).
Michot and Pinnavaia, 1991; Lagaly, 1995). Adsorption of organic cations on PCs has been recently studied by Mishael et al. (1999). Pillared clays are expected to be effective adsorbents for anions at the positive sites of clays that were characterized as Bronsted and Lewis acid sites (Occelli and Tindwa, 1983; Zubkov et al., 1994). Information on adsorption of anions on PCs is scarce. Anion adsorption regulates the migration of anions within the soil profile as well as access of nutrient substances to plants.

Our aim was to study the adsorption of several anions on PC. Sulfate and acetate are of interest as components of soil solution that are of ecological and agronomic importance. Sulfometuron 2-[3-(4,6-dimethylpyrimidin2-yl)ureidosulfonylbenzoic acid is a sulfonylurea preemergence and post-emergence herbicide controlling annual and perennial grasses and broad-leaved weeds. The structure and dissociation of sulfometuron is shown in Fig. 1. Sulfonylureas are weakly acidic compounds with $\mathrm{pK}_{\mathrm{a}}=5.3$ (Worthing, 1983) that are mobile in soils (Beyer et al., 1988). A serious problem encountered is their leaching to deep soil layers and ground water, especially at soil $\mathrm{pH}>7.5$ (Strek, 1998). To reduce undesirable herbicide leaching and migration, PC-herbicide formulations were developed previously for the herbicide alachlor (Gerstl et al., 1998). We aim to design a formulation of sulfometuron that would reduce its leaching, and in this context the study of adsorption of sulfometuron on $\mathrm{PC}$ is particularly important.

\section{MATERIALS AND METHODS}

The pillared acid-activated clay was prepared in large quantities at the National Technical University of Athens and Straton Hi-Tec, Athens, Greece, as described in Jones et al. (1997). The acid-activated precursor montmorillonite is sold under the name Fulcat F22B (Laporte, London, UK). The Al-pillaring of this matrix was performed using aluminum chlorohydrate (ACH) solutions. Typically, the intercalation of the polycations was from solutions with $6 \mathrm{mmol}$ of aluminum per gram of clay. Exchange was at room temperature after aging of the aluminum solution at $80^{\circ} \mathrm{C}$. The amount of intercalated aluminum is always lower in F22B than in the parent clay prior to acid activation, reflecting the decreased cation exchange capacity (CEC) of the clay after acid treatment. After calcination between 400 and $600^{\circ} \mathrm{C}$, a basal space is observed at 1.72 $\mathrm{nm}$. The CEC of the clay is $0.53 \mathrm{mmol}_{\mathrm{c}} \mathrm{g}^{-1}$ and the specific surface area is $256 \mathrm{~m}^{2} \mathrm{~g}^{-1}$ (Jones et al., 1997). Sulfometuron (analytical grade) was obtained from E.I. Du Pont de Nemours \& Company (Wilmington, DE). Analytical grade salts $\mathrm{NaCl}, \mathrm{Na}_{2} \mathrm{SO}_{4}$, and $\mathrm{CH}_{3} \mathrm{COONa}$ were purchased from Frutaron (Haifa, Israel), J.T. Baker (Phillipsburg, NJ), and Merck (Darmstadt, Germany), respectively. HPLC-grade acetonitrile and methanol were obtained from BDH Chemicals

Abbreviations: $\mathrm{PC}$, pillared clay; $\mathrm{CEC}$, cation exchange capacity. 


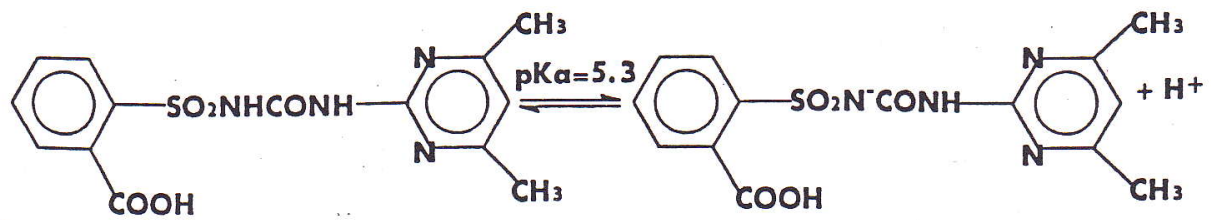

Fig. 1. Structure and dissociation of sulfometuron.

(Poole, England) and trifluoroacetic acid was purchased from Merck (Hohenbrunn, Germany).

Before the measurement of adsorption of sulfate and acetate, the clay was washed by distilled water (clay/water ratio was 1:30). Suspensions were centrifuged for $10 \mathrm{~min}$ at $15000 \mathrm{~g}$ and the supernatant was discarded. After 10 washings the clay was air-dried. The amount of sulfate in the washed clay was $0.008 \mathrm{~mol}_{\mathrm{c}} \mathrm{kg}^{-1}$ (unwashed sample contained $0.41 \mathrm{~mol}_{\mathrm{c}} \mathrm{kg}^{-1}$ ). $\mathrm{X}$-ray diffraction (XRD) measurements of the clay-oriented samples showed that the c-spacing did not change after washing.

Experimental conditions in adsorption measurements of sulfometuron are listed in Table 1 . The adsorption experiments were carried out in $50 \mathrm{ml}$ centrifuge tubes by mixing $0.1 \mathrm{~g}$ or $0.01 \mathrm{~g}$ clay with $20 \mathrm{ml}$ of solutions containing given amounts of stock solutions of anions. To study the effect of the different concentrations of electrolytes on the adsorption of sulfometuron, the $20 \mathrm{ml}$ volume was reached by using one of the following background electrolytes: 1, 10, 100, and 500 $\mathrm{m} M \mathrm{NaCl}, 10 \mathrm{~m} M \mathrm{Na}_{2} \mathrm{SO}_{4}$, and $20 \mathrm{~m} M \mathrm{CH}_{3} \mathrm{COONa}$.

In measurements of sulfate or acetate adsorption the electrolyte solutions were added to the washed, $5 \mathrm{~g} \mathrm{~kg}^{-1}$ clay suspension in the range 0 to $5 \mathrm{mmol}_{c} \mathrm{~g}^{-1}$. To study the competitive adsorption of sulfate and acetate, solutions with equivalent amounts of both anions were added simultaneously. In measurements of successive adsorption of sulfate and acetate, solutions containing 5 or $20 \mathrm{~m} M_{\mathrm{c}}$ sulfate were added to $0.1 \mathrm{~g}$ of clay. After $24 \mathrm{~h}$ of agitation, samples were centrifuged (see below), supernatants were discarded, and $\mathrm{SO}_{4}^{2-}$ was measured; then solutions containing 5 or $20 \mathrm{~m} M_{\mathrm{c}}$ of acetate were combined with the samples containing the same added amounts of sulfate. Acetate and sulfate were determined in supernatants after $24 \mathrm{~h}$ of equilibration. To study the effect of $\mathrm{NaCl}$ on sulfate or acetate adsorption, solutions containing 5 or 20 $\mathrm{m} M_{\mathrm{c}}$ of sulfate or acetate were adjusted to $20 \mathrm{ml}$ by $\mathrm{NaCl}$ solutions and added to $0.1 \mathrm{~g}$ of clay. The concentrations of $\mathrm{NaCl}$ in the added solutions were 100 or $500 \mathrm{~m} M$. The adsorption of chloride was determined by adding $20 \mathrm{ml}$ of $5,20,50$, 100,200 , or $500 \mathrm{mM} \mathrm{NaCl}$ solutions to $0.1 \mathrm{~g}$ of clay.

In all experiments the tubes were kept at $25 \pm 1^{\circ} \mathrm{C}$ under continuous agitation for $24 \mathrm{~h}$, which was sufficient for reaching equilibration of all anions: the adsorbed amounts were found the same for 24,48 , and $72 \mathrm{~h}$. Then the tubes were centrifuged for $10 \mathrm{~min}$ at $15000 \mathrm{~g}$ and the $\mathrm{pH}$ of supernatants was measured.

Desorption was studied for sulfometuron adsorbed from water solutions and acetonitrile. Samples with pre-adsorbed herbicide were air-dried in centrifuge tubes. Then $20 \mathrm{~mL}$ of distilled water or $100 \mathrm{mM} \mathrm{NaCl}$ were added to the clayherbicide complex. Clay concentration was $5 \mathrm{~g} \mathrm{~kg}^{-1}$. The tubes were kept at $25 \pm 1^{\circ} \mathrm{C}$ under continuous agitation during $24 \mathrm{~h}$ and then were centrifuged for $10 \mathrm{~min}$ at $15000 \mathrm{~g}$.

For sulfometuron analysis all supernatants were filtered with teflon filters (ISI, Petach Tikva, Israel) of $0.2 \mathrm{~mm}$ pore in diameter. Sulfometuron was analyzed by HPLC (Merck Hitachi 6200, Tokyo, Japan) equipped with PDA detector set at a wavelength of $232 \mathrm{~nm}$. The reverse phase column was LiChrospher 100 RP-18 (5 $\mu \mathrm{M})$ (Merck, Darmstadt, Germany), and the mobile phase was a mixture of $70 \%$ acetonitrile and $30 \%$ water solution of $0.65 \mathrm{mM}$ trifluoroacetic acid. The flow rate was $1.0 \mathrm{~mL} \mathrm{~min}{ }^{-1}$.

For sulfate and acetate analysis the supernatants were filtered through Acrodisc filters (Gelman Science, Ann Arbor, MI) with $0.2 \mathrm{~mm}$ pore diameter. Sulfate and acetate were analyzed by a DX-300 Ion Chromatograph (Dionex, Sunnyvale, $\mathrm{CA}$ ), equipped with micromembrane suppressor and electroconductivity detector. A guard column AG 4A and an analytical column AS 4A were used. The eluents used were $1.8 \mathrm{mM} \mathrm{Na} \mathrm{CO}_{3}+1.7 \mathrm{mM} \mathrm{NaHCO}$ and $5 \mathrm{mM} \mathrm{Na} \mathrm{B}_{4} \mathrm{O}_{7}$ for the analysis of sulfate and acetate, respectively.

Aluminum species in solutions were determined using inductively coupled plasma atomic emission spectrometer (Spectra, Kleve, Germany).

To pursue the study of binding affinity the adsorbed amounts of the anions when added alone were simulated by means of the Scatchard equation, which is based on the assumption of the lack of cooperativity between adsorbed molecules. The Scatchard equation is equivalent to the Langmuir equation; it includes two parameters: the binding coefficient, $k\left(\mathrm{M}^{-1}\right)$, and the number of surface sites $N$, per particle (e.g., a clay platelet). As elaborated (Nir et al., 1994) there is mathematical equivalence between (i) sorption on particles including $N$ binding sites and (ii) a bimolecular association between the adsorbed molecules and the surface sites, by using the substitution $R_{0}=N G_{0}$, in which $R_{0}$ is total molar concentration of the surface sites and $G_{0}$ is the molar concentration of sorbing particles. The Scatchard equation can be brought to a form:

$$
\alpha=\left(L_{0}-L\right) / L=R_{0} k /(1+k L)
$$

in which $L_{0}$ and $L$ denote the molar concentration of total added herbicide molecules and those remaining free and $\alpha$ is the ratio between sorbed and free herbicide molecules. Eq. [1] can be brought to a quadratic equation:

$$
\alpha^{2}+\alpha\left[1+k\left(L_{0}-R_{0}\right)\right]-k R_{0}=0
$$

The concentration of sorbed molecules is given by:

$$
L_{0}-L=L_{0} \alpha /(1+\alpha)
$$

The parameter $R_{0}$ was fixed by a multiplication of an arbitrary value of the anion exchange capacity of the clay (the maximal amount of the acetate adsorbed, mol $_{c} \mathrm{~g}^{-1}$ clay) with the concentration of the clay $\left(\mathrm{g} \mathrm{kg}^{-1}\right)$.

To compare experimental data and theoretical values statistical criteria used were the closeness of $R^{2}$ to unity and minimal value of the root mean square error (RMSE). The RMSE is defined by:

Table 1. Experimental conditions in adsorption measurements of sulfometuron.

\begin{tabular}{lclc}
\hline Sample & $\begin{array}{c}\text { Clay } \\
\text { concentration }\end{array}$ & Solvent & $\begin{array}{c}\text { Range of } \\
\text { sulfometuron }\end{array}$ \\
\hline Washed and unwashed & $\mathrm{g} \mathrm{kg}^{-1}$ & & $\mathbf{m m o l ~ ~ k g ^ { - 1 }}$ \\
Unwashed & 5.0 & Water & $0-2.85$ \\
Unwashed & 0.5 & Water & $0-68$ \\
Unwashed & 5.0 & Acetonitrile & $0-550$ \\
\hline
\end{tabular}




$$
\operatorname{RMSE}=\left[\sum_{i=1}^{n}\left(y_{\text {calc, }}-y_{\text {exp. }}\right)^{2} /(n-p)\right]^{1 / 2}
$$

in which $y_{\text {calc, }}$ is the calculated amount $\left(\mathrm{mol} \mathrm{kg}^{-1}\right)$ of the cation under consideration, $y_{\text {exp, } i}$ is the experimental value, $n$ is the number of data points, and $p$ is the number of adjustable parameters (i.e., binding constants), which are determined by employing a particular set of data points.

\section{RESULTS AND DISCUSSION}

\section{Sulfometuron}

The adsorption isotherm of sulfometuron from water solutions on PC is presented in Fig. 2. The low solubility of sulfometuron in water [10 $\mathrm{mg} \mathrm{L}^{-1}$ (Worthing, 1983), $6.4 \mathrm{mg} \mathrm{L}^{-1}$ (EXTOXNET data)] at $\mathrm{pH}$ below neutral set a limit on the added amounts. The amounts of sulfometuron adsorbed reached 95 to $98 \%$ of added for unwashed samples and 80 to $96 \%$ for washed samples, but the maximal weight percent of sulfometuron adsorbed was only $0.1 \%$. The $\mathrm{pH}$ values of both supernatant solutions did not change with adsorption of sulfometuron; $\mathrm{pH}$ values after adsorption were $6.0 \pm 0.1$ and $7.0 \pm$ 0.1 for unwashed and washed samples, respectively. In both cases $\mathrm{Al}$ was not released from the surface. Adsorption of sulfometuron decreased with an increase in $\mathrm{pH}$, as was previously found for primisulfuron, another sulfonylurea herbicide (Ukrainczyk and Ajwa, 1996). Our explanation is that the anionic form is adsorbed on the positively charged sites of the surface (i.e., pillars). The $\mathrm{pH}$ values of the suspension of the unwashed and washed clay were 4.63 and 5.46 , respectively. Washing reduced 140 -fold the concentration of $\mathrm{Al}$ species in the supernatant, from 0.47 to $0.0033 \mathrm{mg} \mathrm{L}^{-1}$ in washed samples. An increase in $\mathrm{pH}$ coupled with decrease in the concentration of $\mathrm{Al}$ species in the supernatant solution indicated a decrease in the number of positively charged sites on the clay surface after washing. The positively

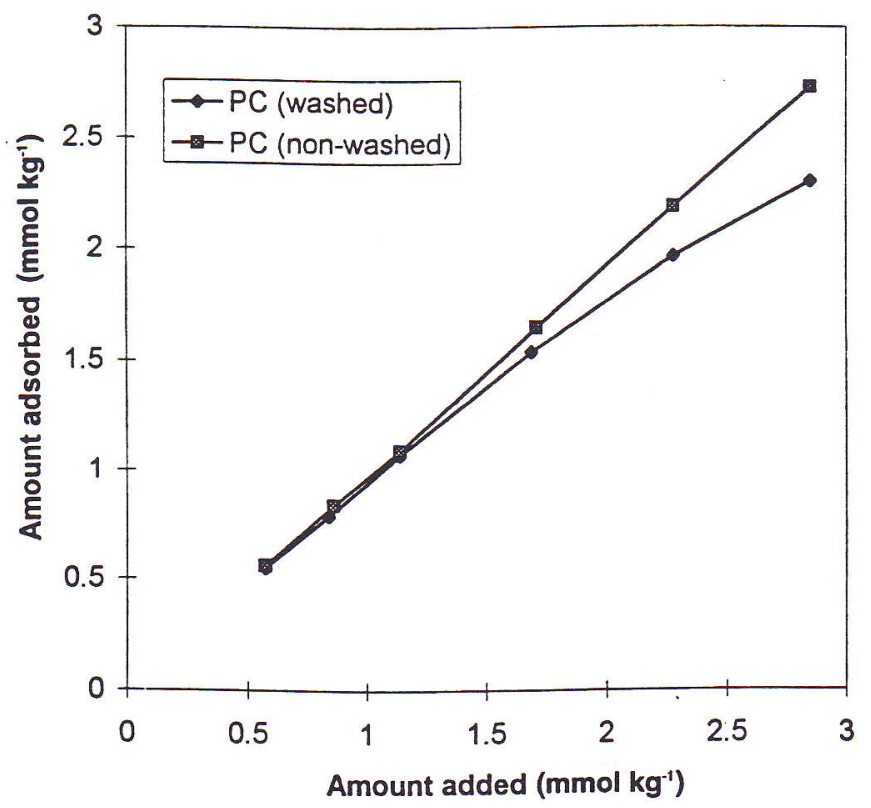

Fig. 2. Adsorption of sulfometuron from water solutions on pillared clay. charged sites of PCs are attributed to both Brønsted and Lewis acidities (Schutz et al., 1987, Zubkov et al., 1994), but the surface acidity of the material after calcination is mostly of Lewis type due to the pillars (Occelli and Tindwa, 1983). We expect the adsorption of sulfometuron on PC to be due to electrostatic interactions of the anion with the positively charged sites of the pillars.

In an attempt to increase the low weight percent of the adsorbed sulfometuron with respect to clay we decreased the clay concentration. The 20 -fold increase in herbicide load resulted in a slight increase in the maximal adsorption $\left(3.22 \mu \mathrm{mol} \mathrm{g}^{-1}\right.$ for $0.5 \mathrm{~g} \mathrm{~kg}^{-1}$ suspension versus $2.72 \mu \mathrm{mol} \mathrm{g}^{-1}$ for $5 \mathrm{~g} \mathrm{~kg}^{-1}$ suspension). The frac: tion of sulfometuron adsorbed in the more dilute clay suspension was much lower, 5 to $16 \%$ of the amount added, and $\mathrm{pH}$ values of the supernatants after adsorption were $7.4 \pm 0.1$.

In order to increase the amounts of sulfometuron present in suspension, its adsorption from acetonitrile solution was considered (Fig. 3). The adsorbed amount of sulfometuron reached $11 \%$ of the amount initially added, which is $2 \%$ of the clay weight. The relative adsorption is not significant due to the stronger interactions of sulfometuron molecules with those of acetonitrile. The maximum of sulfometuron adsorption from methanol (isotherm not shown) was $3.3 \mathrm{mmol} \mathrm{kg}^{-1}$ (i.e., $6 \%$ of the amount added and $0.12 \%$ of the clay weight).

The effect of $\mathrm{NaCl}$ or $\mathrm{Na}_{2} \mathrm{SO}_{4}$ on sulfometuron adsorption was insignificant. For $2.28 \mathrm{mmol} \mathrm{kg}^{-1}$ of sulfometuron added, the maximum reduction of the adsorbed amounts was $4 \%$ for $500 \mathrm{mM} \mathrm{NaCl}$ and $5 \%$ for $10 \mathrm{mM}$ $\mathrm{Na}_{2} \mathrm{SO}_{4}$. On the other hand, the addition of $\mathrm{CH}_{3} \mathrm{COONa}$ was more effective in reducing the adsorption of sulfometuron. For $0.86 \mathrm{mmol} \mathrm{kg}^{-1}$ and $2.28 \mathrm{mmol} \mathrm{kg}^{-1}$ added, the adsorbed amounts of sulfometuron decreased by 6 and $8 \%$, respectively at the $1: 1$ sulfometuron/acetate ratio, by 15 and $21 \%$ at $1: 100$ sulfometuron/acetate ratio, and by $22 \%$ and $32 \%$ at $1: 1000$ sulfometuron/acetate ratio. It appears that sulfometuron is tightly bound to some surface sites that are not affected by electrolyte screening and that acetate, unlike chloride and sulfate, competes with sulfometuron for these sites. Acetate as well as sulfometuron are weak bases with $\mathrm{pK}_{\mathrm{a}} 4.8$ and

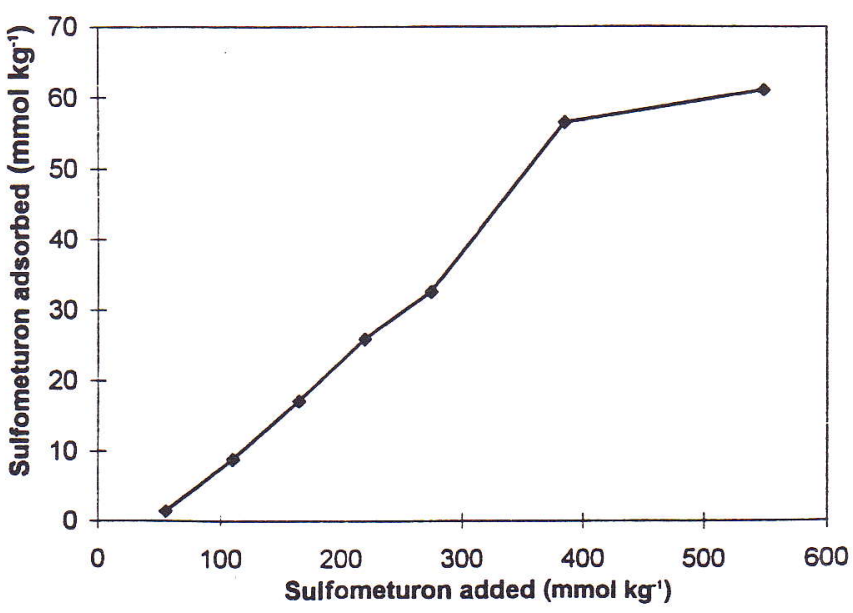

Fig. 3. Adsorption of sulfometuron from acetonitrile on pillared clay. 
Table 2. Desorption of sulfometuron from pillared clay.

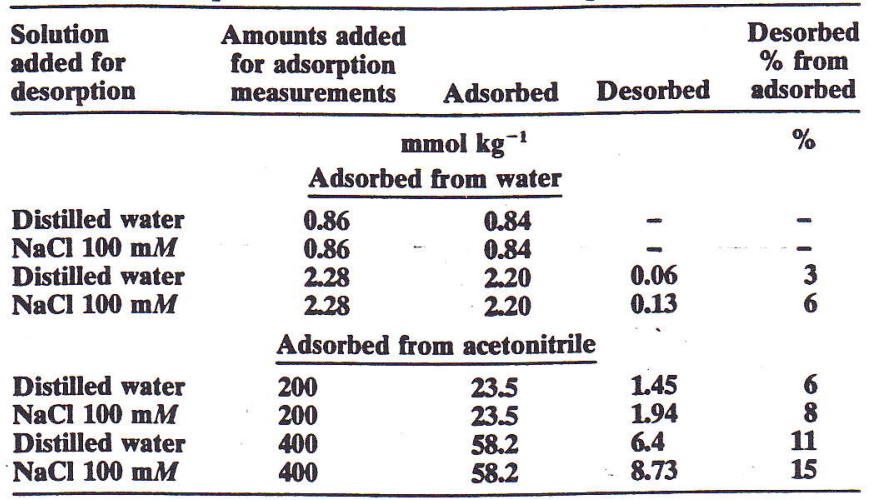

5.3 respectively (Lide, 1991; Worthing, 1983). Both anions can participate in acid-base reactions with positively charged sites of PC.

The results of the desorption measurements are presented in Table 2. Sulfometuron adsorbed from water solution was slightly desorbed. Desorption of sulfometuron adsorbed from acetonitrile was somewhat higher. In both cases more sulfometuron desorbed from a solution of $100 \mathrm{mM} \mathrm{NaCl}$ than from water. The explanation is that sulfometuron as an anion is more stable in solution of high ionic strength than in water. The insignificant desorption of sulfometuron adsorbed from water solutions confirms the hypothesis for tight binding of sulfometuron on PC.

\section{Acetate}

The adsorption isotherm of acetate on PC is presented in Fig. 4. The adsorbed values were high-up to 0.41 $\mathrm{mmol}_{\mathrm{c}} \mathrm{g}^{-1}$. Figure 5a shows the constant increase in supernatant $\mathrm{pH}$ values with increasing acetate adsorption. Schulthess and McCarthy (1990) suggested two mechanisms of acetate adsorption on aluminum oxide: ligand exchange and hydrogen bonding. Based on the constant $\mathrm{pH}$ increase with acetate adsorption, we proposed that the dominant mechanism of adsorption of acetate on PC is inner-sphere complexation (i.e., exchange with surface hydroxyls). Our hypothesis was confirmed by the calculations of the slope of pAc versus pOH, which was $0.83\left(R^{2}=0.978\right)$.

The presence of equivalent amounts of chloride ( 5 or $20 \mathrm{mM}$ ) as the background electrolyte decreased acetate adsorption by 5 and $54 \%$. Addition of 100 and $500 \mathrm{mM}$ of $\mathrm{NaCl}$ strongly reduced acetate adsorption (Table 3 ). Schulthess and McCarthy (1990) found significant decrease in acetate adsorption on aluminum oxide with the addition of chloride. Their explanation was that both anions adsorb on the same sites but by different mechanisms. Thus, chloride, usually considered as adsorbed by outer-sphere complexation, when added in high amounts can compete with acetate adsorbed by inner-sphere complexation. Adsorption of chloride alone on clay was high: $0.15 \mathrm{mmol}_{\mathrm{c}} \mathrm{g}^{-1}$ for $20 \mathrm{mM}, 0.28$ $\mathrm{mmol}_{\mathrm{c}} \mathrm{g}^{-1}$ for $100 \mathrm{mM}$, and $0.31 \mathrm{mmol}_{\mathrm{c}} \mathrm{g}^{-1}$ for $500 \mathrm{mM}$ added $\mathrm{NaCl}$; for $5 \mathrm{mM}$ added adsorption of chloride was very low $\left(0.01 \mathrm{mmol}_{\mathrm{c}} \mathrm{g}^{-1}\right)$ and didn't affect the adsorption of acetate (Table 3 ). Thus chloride added in

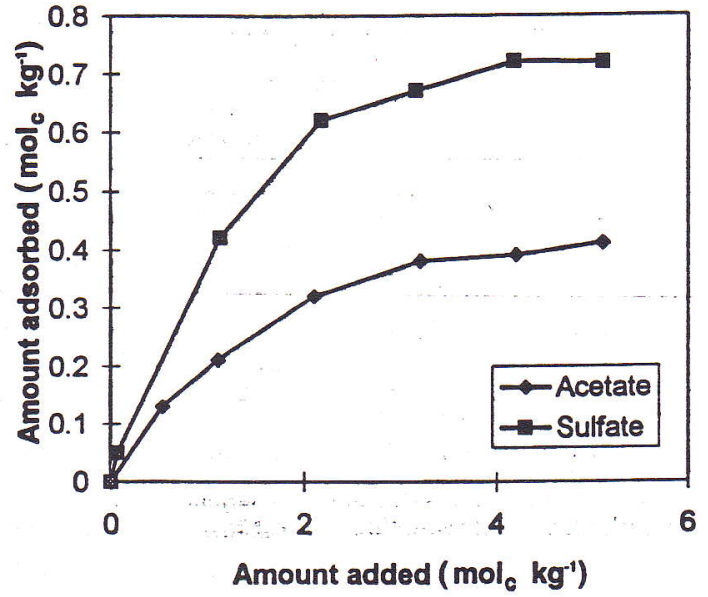

Fig. 4. Adsorption of sulfate and acetate on pillared clays.

small amounts does not compete with acetate for surface sites. Sulfate added simultaneously with acetate at the same equivalent amounts did not affect significantly the adsorption of acetate (Table 4).

The high adsorption of several monovalent organic cations (dyes) on PC in the presence of 100 and 500 $\mathrm{mM}$ of $\mathrm{NaCl}$ solutions was explained by the reduction of the positive potential of the surface. The positive potential on the negatively charged planes of $\mathrm{PC}$ is raised as a result of charge reversal of the surface when dyes adsorb above the CEC (Mishael et al., 1999). The significant adsorption of chloride on PC from 100 and $500 \mathrm{mM}$ of $\mathrm{NaCl}$ solutions with accompanying increase
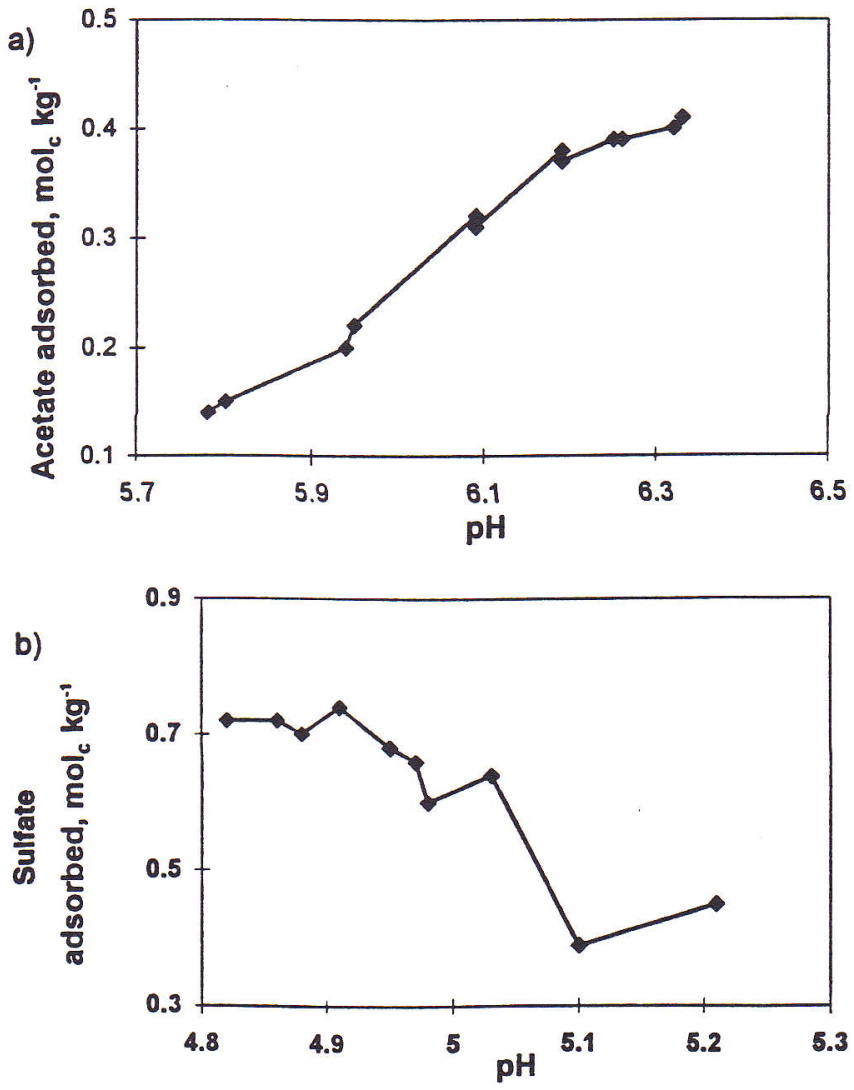

Fig. 5. The pH of equilibrium solutions versus amounts of sulfate and acetate adsorbed. 
Table 3. Adsorption of sulfate and acetate on pillared clay in the presence of $\mathrm{NaCl}$.

\begin{tabular}{llccc}
\hline $\begin{array}{l}\text { NaCl } \\
\text { added }\end{array}$ & Anion & $\begin{array}{c}\text { Anion } \\
\text { added }\end{array}$ & $\begin{array}{c}\text { Anion } \\
\text { adsorbed }\end{array}$ & $\begin{array}{c}\text { Reduction in } \\
\text { adsorption } \dagger\end{array}$ \\
\hline $\mathbf{m M}$ & & $\mathbf{m M}_{\mathrm{c}}$ & mol $_{\mathrm{e}} \mathbf{k g}^{-1}$ & $\%$ \\
100 & $\mathrm{SO}_{4}^{2-}$ & 5 & - & 100 \\
100 & $\mathrm{SO}_{4}^{2-}$ & 20 & 0.10 & 86 \\
500 & $\mathrm{SO}_{4}^{2-}$ & 20 & - & 100 \\
5 & $\mathrm{CH}_{3} \mathrm{COO}^{-}$ & 5 & 0.20 & 5 \\
20 & $\mathrm{CH}_{3} \mathrm{COO}^{-}$ & 20 & 0.21 & 54 \\
100 & $\mathrm{CH}_{3} \mathrm{COO}^{-}$ & 5 & 0.021 & 90 \\
100 & $\mathrm{CH}_{3} \mathrm{COO}^{-}$ & 20 & 0.15 & 62 \\
500 & $\mathrm{CH}_{3} \mathrm{COO}^{-}$ & 5 & - & 100 \\
500 & $\mathrm{CH}_{3} \mathrm{COO}^{-}$ & 20 & - & 100 \\
\hline
\end{tabular}

† Reduction in adsorption is ratio between sulphate or acetate amounts adsorbed without and with addition of $\mathrm{NaCl}$.

in the negative charge of the clay might be an additional factor contributing to the high adsorption of dyes above the CEC.

\section{Sulfate}

The adsorption isotherm of sulfate is shown in Fig. 4. The adsorbed amounts of sulfate (negative charges) were higher than for acetate, with a maximum adsorbed amount of $0.72 \mathrm{mmol}_{\mathrm{c}} \mathrm{g}^{-1}$. In contrast to the $\mathrm{pH}$ increase observed during acetate adsorption, the sulfate adsorption resulted in a pH decrease (Fig. $5 \mathrm{~b}$ ) and an increase in the $\mathrm{Al}$ species concentration in the supernatant solutions (Fig. 6). The $\mathrm{pH}$ decrease with the increase of sulfate adsorption was observed for Ultisols containing significant amounts of aluminum oxides (Pachepsky et al., 1994). The increased dissolution of Al species with the increase of sulfate adsorption was found for $\gamma-\mathrm{Al}_{2} \mathrm{O}_{3}$ (He et al., 1996). One of the mechanisms proposed for sulfate adsorption on aluminum oxides is exchange of sulfate with the surface hydroxyl (Parfit, 1978; Rajan, 1978). This mechanism was considered as inner-sphere complexation (He et al., 1996). Curtin and Syers (1990a) observed a $\mathrm{pH}$ increase with the increase of sulfate adsorption by soils, which is in agreement with the hydroxyl exchange into solution. Another proposed mechanism for sulfate adsorption is formation of outersphere complexes (Davis and Leckie, 1980; Sposito, 1984; He et al., 1996):

$$
\begin{aligned}
\mathrm{MOH}_{2}^{+}(\mathrm{s})+\mathrm{SO}_{4}^{2-}(\mathrm{aq}) & =\mathrm{MOH}_{2}^{+} \mathrm{SO}_{4}^{2-}(\mathrm{s}) \\
\mathrm{MOH}_{2}^{+}(\mathrm{s})+\mathrm{HSO}_{4}^{-}(\mathrm{aq}) & =\mathrm{MOH}_{2}^{+} \mathrm{HSO}_{4}^{-}(\mathrm{s})
\end{aligned}
$$

Table 4. Competitive adsorption of sulfate and acetate on pil-

\begin{tabular}{|c|c|c|c|}
\hline \multicolumn{2}{|c|}{ Anion added } & \multicolumn{2}{|c|}{ Anion adsorbed } \\
\hline $\mathrm{CH}_{3} \mathrm{COO}^{-}$ & $\mathrm{SO}_{4}^{2-}$ & $\mathrm{CH}_{3} \mathrm{COO}^{-}$ & $\mathrm{SO}_{4}^{2-}$ \\
\hline & 11 & & \\
\hline 0 & 1.1 & 0 & $\begin{array}{l}0.42 \\
0.67\end{array}$ \\
\hline 0 & $\begin{array}{l}3.2 \\
4.2\end{array}$ & 0 & 0.72 \\
\hline 1.1 & 0 & 0.21 & 0 \\
\hline 3.2 & 0 & 0.38 & 0 \\
\hline 4.2 & 0 & 0.39 & 0 \\
\hline 1.1 & 1.1 & 0.18 & 0.05 \\
\hline 3.2 & 3.2 & ndt & 0.02 \\
\hline 4.2 & 4.2 & 0.38 & 0.01 \\
\hline
\end{tabular}
lared clay.

$\uparrow$ Not determined.



Fig. 6. Al species (concentrations in $\mathrm{mg} \mathrm{L}^{-1}$ ) versus $\mathrm{pH}$ in equilibrium solutions after sulfate adsorption.

where $\mathrm{M}$ is metal cation and $\mathrm{OH}_{2}^{+}(\mathrm{s})$ is the inorganic surface hydroxyl group. Zhang and Sparks (1990) concluded that sulfate adsorbed on goethite by outersphere complexation.

Adsorption of sulfates on hydrous alumina and positively charged soils is accompanied by an increase in the negative charge of the surface and some increase in cation adsorption (Rajan 1978; Curtin and Syers, 1990a).

Sulfate can be adsorbed on PC by outer-sphere complexation, which results in an increase of the negative charge of the surface. However, as will be elaborated when discussing binding affinities, an additional mode of inner-sphere complexation cannot be ruled out. The increase of the negative charge on the clay surface may lead to an additional adsorption of $\mathrm{Na}^{+}$on the surface from $\mathrm{Na}_{2} \mathrm{SO}_{4}$ solutions and formation of sodium aluminum sulfate salts on the clay surface. The solubility of potassium aluminum sulfate in the range of $\mathrm{pH}$ studied is almost 10 times higher than that of gibbsite (Lindsay, 1979). However, the solubility of sodium aluminum sulfate is almost 10 times higher than that of potassium aluminum sulfate (Lide, 1991), which results in an increased concentration of $\mathrm{Al}$ species in the supernatant. Thus, hydrolysis of aluminum species leads to a decrease in the $\mathrm{pH}$ of supernatant solutions with the increase in sulfate adsorption.

Addition of equivalent concentrations of acetate simultaneously with sulfate resulted in a drastic decrease in sulfate adsorption (Table 4). On the other hand, acetate adsorption was insignificant when the clay was preadsorbed with sulfate; desorption of sulfate by acetate was $10 \%$ at $5 \mathrm{~m} M_{\mathrm{c}}$ and $13 \%$ at $20 \mathrm{~m} M_{\mathrm{c}}$ acetate added. Hence, the dramatic decrease in sulfate adsorption when added simultaneously with acetate can be explained by a kinetic effect (i.e., by differences in the rates of their adsorption/desorption). According to Table 5 the binding coefficient of sulfate is two times larger than that of acetate. The binding coefficient, $k$ is given by $k=$ $C / D$, where $C$ and $D$ are the forward and backward rate 
Table 5. Parameters describing adsorption of several anions on pillared clay.

\begin{tabular}{|c|c|c|c|c|}
\hline Anion & $k$ & $\boldsymbol{R}^{2}$ & RMSE & $\begin{array}{c}\text { Range of } \\
\text { adsorbed amount }\end{array}$ \\
\hline & $\mathbf{M}^{-1}$ & & - & $\mathrm{nmol} \mathrm{kg}^{-1}$ \\
\hline $\begin{array}{l}\text { Sulfometuron } \\
\text { (from water solutions) }\end{array}$ & 12000 & 1 & 0.012 & $0.57-2.85$ \\
\hline $\begin{array}{l}\text { Sulfometuron } \\
\quad \text { (from acetonitrile) } \\
\text { Acetate } \\
\text { Sulphate } \\
\text { Chloride }\end{array}$ & $\begin{array}{r}67 \\
350 \\
650 \\
15\end{array}$ & $\begin{array}{l}0.875 \\
0.914 \\
0.996 \\
0.949\end{array}$ & $\begin{array}{c}7.5 \\
33 \\
8 \\
32\end{array}$ & $\begin{array}{r}8.8-61 \\
130-410 \\
25-359 \\
10-310\end{array}$ \\
\hline
\end{tabular}

constants of adsorption. It is possible that both $C$ - and $D$-values are larger for acetate than for sulfate. Possible explanation for this dramatic reduction in sulfate adsorption may be due to steric restrictions imposed by bound acetate ions. On the other hand, the low desorption of pre-adsorbed sulfate upon addition of acetate indicates a strong adsorption of sulfate. Thus, it appears that sulfate and acetate compete for the same adsorption sites and that sulfate also can be adsorbed by innersphere complexation on PC. The increase in hydroxyl concentration in supernatant solution accompanying the inner-sphere complexation cannot be detected in this case, because of hydrolysis of aluminum species, which results in evident pH decrease. Adding 100 and $500 \mathrm{mM}$ of $\mathrm{NaCl}$ reduced drastically sulfate adsorption (Table 4). Curtin and Syers (1990b) showed a decrease in sulfate adsorption on positively charged soils with addition of chloride. Thus, chloride can compete with sulfate for the adsorption sites.

The results of the calculation of binding coefficients by using the Scatchard equation are shown in Table 5. Generally, Eq. [1] can provide both parameters, $R_{0}$ and $k$. However, since a minimal number of parameters is preferred, we present results based on the use of a single parameter, $k$. The parameter $R_{0}$ was fixed by a multiplication of the plateau value for acetate adsorption on the clay mineral $(0.42 \mathrm{mmol})$ with the concentration of the clay $\left(\mathrm{g} \mathrm{kg}^{-1}\right)$. The applicability of the Scatchard equation (Eq.[1]) was tested by its ability to adequately simulate the sorption results.

In principle, the Scatchard equation should fail to simulate the adsorption of particles that charge the surface, since this process should result in progressive inhibition of the adsorption of additional charged particles, or negative cooperativity. Due to the geometrical and charge heterogeneity of the PC we avoid an attempt to develop a more refined treatment that would consider changes in surface potential due to adsorption and changes in ionic strength (Nir, 1986).

The results in Table 5 demonstrate that the Scatchard equation yields a very good simulation for the adsorbed amounts of sulfometuron and a good fit for those of sulfate. The outcome that sulfometuron adsorption is very well explained is not surprising because the largest adsorbed amount is a small fraction of the total number of adsorption sites. The fact that a good fit also is obtained for $\mathrm{SO}_{4}^{2-}$ adsorption indicates that its adsorption is accompanied by $\mathrm{Na}^{+}$adsorption and does not result in charging of the surface. Similarly, the adsorption of acetate that results in a release of $\mathrm{OH}^{-}$does not result in charging of the surface. As expected, the binding coefficient $k$ for sulfometuron adsorption is much larger than that of acetate or sulfate. The binding coefficient for sulfate adsorption is two times larger than that of acetate, which is consistent with the low desorption of sulfate by acetate and the hypothesis about outer- and inner-sphere complexation of sulfate on the surface of PC. The binding coefficient for chloride is much less than for the other anions. As a monovalent anion adsorbed by outer-sphere complexation, chloride can compete with sulfate and acetate when added in large excess, but it does not compete with sulfometuron.

According to our results, the sequence of adsorption affinity of anions on the PC surface is sulfometuron $>>$ sulfate $>$ acetate $>>$ chloride.

\section{CONCLUSIONS}

- Pillared clay is a very effective adsorbent of anions from aqueous solutions. Desorption of sulfometuron adsorbed on PC from water solutions is low; sulfometuron appears to be tightly bound to the PC surface. These characteristics suggest that PC may be useful for the preparation of clay-sulfometuron formulations.

- When added in the range of more than $1 \mathrm{~mol}_{\mathrm{c}} \mathrm{kg}^{-1}$, anions compete for the same adsorption sites of PC, but the mechanisms of adsorption can be different.

- The main mechanisms suggested for the adsorption of the studied anions are:

Sulfometuron. Strong electrostatic interactions constitute the dominant mode. The final $\mathrm{pH}$ is the same as in aqueous solutions of sulfometuron and $\mathrm{Al}$ is not released. Equivalent amounts of acetate do not affect significantly the adsorption of sulfometuron; acetate added in 100- and 1000-fold larger excess competes with sulfometuron for the surface sites, but sulfate and chloride do not.

Sulfate. The proposed interactions are via outer- and inner-sphere complexation. The $\mathrm{pH}$ is reduced with sulfate adsorption and $\mathrm{Al}$ is released. Adsorption of sulfate in the presence of acetate and high chloride concentrations is drastically reduced, but desorption of pre-adsorbed sulfate by acetate is minimal.

Acetate. The proposed mode is mainly via innersphere complexation. The $\mathrm{pH}$ increases with acetate adsorption, indicating exchange of acetate with surface hydroxyls. Aluminum is not released; sulfate does not affect acetate adsorption when both anions are added simultaneously, but pre-adsorbed sulfate prevents acetate adsorption. Small concentrations of chloride do not affect the adsorption of acetate, but high concentrations of chloride reduce acetate adsorption.

Chloride. When added in high concentrations chloride can compete with acetate for adsorption on the surface sites, although the proposed mechanism for chloride adsorption is outer-sphere complexation.

- The sequence of adsorption affinity of anions on the PC surface is sulfometuron $>>$ sulfate $>$ acetate $>$ chloride. 


\section{ACKNOWLEDGMENTS}

This research was supported by Grant 8803-1-96 of the Ministry of Science and Arts, Israel, for French-Israeli collaboration, and partially supported by a Grant G-0405-95 from G.I.F., the German-Israeli Foundation for Scientific Research and Development. Dr. T. Undabeytia acknowledges the Spanish Government (ref. PF9633975424) and the European Community (Contract N. FAIR-BM-970892) for a postdoctoral fellowship at the Seagram Center.

\section{REFERENCES}

Barrer, R.M. 1989. Shape-selective sorbents based on clay minerals: A review. Clays Clay Miner. 37:385-395.

Bergaya, F. 1990. Argiles a piliers. p. 513-537. In A. Decarreau (ed.) Matériaux argile structure, propriétés et application. La Societe Francaise de Minéralogie et de Cristallographie, Paris, France.

Bergaya, F. 1994. Focus on pillaring and mixed Al (13-x) Fe (x) PILCs. CEA-PLS Newsletter 7:11-12.

Bergaya, F. 1995. The meaning of surface area and porosity measurements of clays and pillared clays. J. Porous Materials 2:91-96.

Bergaya, F., L. Gatineau, and H. Van Damme. 1993a. About surface area and porosity measurements in pillared clays. p. 19-26. In C.A.C. Sequeira and M.J. Hudson (ed.) Multifunctional mesoporous solids. Kluwer Academic Publ., Dordrecht, the Netherlands.

Bergaya, F., N. Hassoun, J. Barrault, and L. Gatineau. 1993b. Pillaring of synthetic hectorite by mixed $\left[\mathrm{Al}_{13-\mathrm{x}} \mathrm{Fe}_{\mathrm{x}}\right]$ pillars. Clay Miner. 28:109-122.

Beyer, E.M., M. Duffy, J.V. Hay, and D.D. Schlueter. 1988. Sulfonylureas. p. 117-189. In P.C. Kearney and D.D. Kaufman (ed.) Herbicides: Chemistry, degradation, mode of action. Vol. III. Marcel Decker, New York.

Curtin, D., and J.K. Syers. 1990a. Mechanism of sulphate adsorption by two tropical soils. J. Soil Sci. 41:295-304.

Curtin, D., and J.K. Syers. 1990b. Influence of nitrate and chloride on the adsorption and transport of sulphate in soils. J. Soil Sci. 41: $473-442$.

Davis, J.A., and J.O. Leckie. 1980. Surface ionization and complexation at the oxide/water interface. 3. Adsorption of anions. J. Colloid Interface Sci. 74:32-43.

Gerstl, Z., A. Nasser, and U. Mingelgrin. 1998. Controlled release of pesticides into soils from clay-polymer formulations. J. Agric. Food Chem. 46:3797-3802.

He, L.M., L.W. Zelazny, V.C. Baligar, K.D. Ritchey, and D.C. Martens. 1996. Hydroxy-sulphate exchange stochiometry on $\gamma-\mathrm{A}_{2} \mathrm{O}_{3}$ and kaolinite. Soil Sci. Soc. Am. J. 60:442-452.

Jones, W., G. Poncelet, E. Ruiz-Hutzky, J.S. Galvan, P. Pomonis, H. Van Damme, F. Bergaya, N. Papayannakos, and N. Gangas. 1997. Synthesis, characterization and application of pillared layered solids (PILCs) produced in large quantities. Synthesis Rep. of BriteEuram Contract No. BR2-CT-629 of the European Community.

Lagaly, G. 1995. Surface and interlayer reactions: Bentonites as adsorbents. p. 137-144. In J. Churchman et al. (ed.) Clays controlling the environment. Proc. 10th Int. Clays Conf., Adelaide, Australia. 18-23 July 1993. CSIRO, Melbourne, Australia.

Lahav, N., U. Shani, and I. Shabtai. 1978 Cross-linked smectites. I. Synthesis and properties of hydroxy-aluminium-montmorillonite. Clays Clay Miner. 26:107-115.

Lide, D.R. (ed.). 1991. Handbook of chemistry and physics. 1990-1991. CRC Press, Boston, MA.
Lindsay, W.L. 1979. Chemical equilibria in soils. John Wiley \& Sons New York.

Michot, L.J., and T.J. Pinnavaia. 1991. Adsorption of chlorinated phenols from aqueous solution by surfactant-modified pillared clays. Clays Clay Miner. 39:634-641.

Mishael, Y.G., G. Rytwo, S. Nir, M. Crespin, F. Annabi-Bergaya, and H. Van Damme. 1999. Interactions of monovalent organic cations with pillared clays. J. Colloid Interface Sci. 209:123-128. sfi

Nir, S. 1986. Specific and nonspecific cation adsorption to clays: Solution concentrations and surface potentials. Soil Sci. Soc. Am. J. 50:52-57.

Nir, S., R. Peled, and K.-D. Lee. 1994. Analysis of particle uptake by cells: Binding to several receptors, equilibration time, endocytosis. Colloids Surfaces 89:45-57.

Nolan T., K.R. Srinivasan, and H.S. Fogler. 1989. Dioxon sorption by hydroxy-aluminum-treated clays. Clays Clay Miner. 37:487-492

Occelli, M.L., and R.M. Tindwa. 1983. Physicochemical properties of montmorillonite interlayered with cationic oxyaluminum pillars. Clays Clay Miner. 31:22-28.

Pachepsky, Ya.A., S.A. Ivanova, L.P. Korsunskaya, and T. Polubesova. 1994. Adsorption of $\mathrm{Cl}^{-}, \mathrm{NO}_{3}^{-}$and $\mathrm{SO}_{4}^{2-}$ anions by krasnozem. Agrochimica 38:306-314.

Parfit, R.L. 1978. Anion adsorption by soils and soil materials. Adv Agron. 30:1-50.

Rajan, S.S.S. 1978. Sulphate adsorbed on hydrous alumina, ligands displaced, and changes in surface charge. Soil Sci. Soc. Am. J. 42:39-44.

Schulthess, C.P., and J.F. McCarthy. 1990. Competitive adsorption of aqueous carbonic and acetic acids by an aluminum oxide surfaces on clay minerals. Soil Sci. Soc. Am. J. 54:688-694.

Schutz, A., D. Plee, F. Borg, P. Jacobs, G. Poncelet, and J.J. Fripiat 1987. Acidity and catalytic properties of pillared montmorillonite and beidellite. p. 305-310. In L.G. Schultz et al. (ed.) Proc. Int. Clay Conf., Denver, CO. The Clay Mineral Society, Bloomington, IN.

Sposito, G. 1984. The surface chemistry of soils. Oxford Univ. Press, New York.

Srinivasan, K.R., and H.S. Fogler. 1990. Use of inorgano-organo-clays in the removal of priority pollutants from industrial wastewaters: Structural aspects. Clays Clay Miner. 38:277-286.

Strek, H.J. 1998. Fate of chlorsulfuron in the environment. II. Field evaluations. Pestic. Sci. 53:52-70.

Ukrainczyk, L., and H.A. Ajwa. 1996. Primisulfuron sorption on minerals and soils. Soil Sci. Soc. Am. J. 60:460-467.

Van Damme, H., and J.J. Fripiat. 1985. A fractal analysis of adsorption processes by pillared swelling clays. J. Chem. Phys. 82:2785-2789.

Van Damme, H., P. Levitz, and L. Gatineau. 1986. Energetical and geometrical constraints on adsorption and reaction kinetics on clay surfaces. p. 283-304. In R. Setton (ed.) Chemical reactions in organic and inorganic constrained systems. Reidel, Boston, MA.

Worthing C.R. (ed.). 1983. Pesticide manual. British Crop Protection Council Publ., Lavenham, UK.

Zhang, P.C., and D.L. Sparks. 1990. Kinetics and mechanism of sulphate adsorption/desorption on goethite using pressure-jump relaxation. Soil Sci. Soc. Am. J. 54:1266-1273.

Zielke, R.C., and T.J. Pinnavaia. 1988. Modified clays for the adsorption of environmental toxicants: Bindings of chlorophenols to pillared, delaminated, and hydroxy-interlayered smectites. Clays Clay Miner. 36:403-408.

Zubkov, S.A., L.M. Kustov, V.B. Kazansky, G. Fetter, D. Tichit, and F. Figueras. 1994. Study of the nature of the acid sites of montmorillonite pillared with aluminum and oligosilsequioxane complex cations. I. Bronsted acidity. Clays Clay Miner. 42:421-427. 